\title{
Functional Architecture of Synapses in the Inner Retina: Segregation of Visual Signals by Stratification of Bipolar Cell Axon Terminals
}

\author{
Samuel M. Wu, Fan Gao, and Bruce R. Maple \\ Cullen Eye Institute, Baylor College of Medicine, Houston, Texas 77030
}

We correlated the morphology of salamander bipolar cells with characteristics of their light responses, recorded under voltageclamp conditions. Twelve types of bipolar cells were identified, each displaying a unique morphology and level(s) of axon terminal stratification in the inner plexiform layer (IPL) and exhibiting light responses that differed with respect to polarity, kinetics, the relative strengths of rod and cone inputs, and characteristics of spontaneous EPSCs (sEPSCs) and IPSCs. In addition to the well known segregation of visual information into ON and OFF channels along the depth of the IPL, we found an overlying mapping of spectral information in this same dimension, with cone signals being transmitted predominantly to the central IPL and rod signals being sent predominantly to the margins of the IPL. The kinetics of bipolar cell responses correlated with this segregation of ON and OFF and of rod and cone information in the IPL. At light offset, rod-dominated cells displayed larger slow cationic current tails and smaller rapid overshoot responses than did cone-dominated cells. sEPSCs were generally absent in depolarizing bipolar cells but present in all hyperpolarizing bipolar cells (HBCs) and larger in roddominated $\mathrm{HBCs}$ than in cone-dominated HBCs. Inhibitory chloride currents, elicited both at light onset and light offset, tended to be larger for cone-dominated cells than for roddominated cells. This orderly segregation of visual signals along the depth of the IPL simplifies the integration of visual information in the retina, and it begins a chain of parallel processing in the visual system.

Key words: retina; bipolar cells; light-evoked postsynaptic currents; axon terminal stratification; ON and OFF channels; rod and cone inputs; parallel information processing
In the visual system, the projection of light-evoked signals from the eye to the brain is organized into parallel routes; different classes of retinal ganglion cells carry signals of different qualities, such as color, contrast, and form, to segregated regions in highly organized three-dimensional structures of the lateral geniculate nuclei and the visual cortex (Enroth-Cugell and Robson, 1966; Hubel and Wiesel, 1977; Hubel and Livingstone, 1987). While the retina represents information about positions within the visual world in two dimensions, it also appears to use the orthogonal third dimension (the depth of the retina) to represent qualities of visual stimuli. Anatomical studies suggest that the inner plexiform layer (IPL) of the retina has a highly elaborate sublaminar organization; the axon terminals of bipolar cells and the dendrites of amacrine cells and ganglion cells display widely diverse morphologies, with processes stratifying at many different levels of the IPL (Ramon y Cajal, 1893; Boycott and Dowling, 1969; Kolb, 1982). In mammalian retinas, for example, 1 type of rod bipolar cell and 9-10 types of cone bipolar cells with distinguishable morphology and levels of axon terminal stratification have been identified (Boycott and Wassle, 1991; Euler and Wassle, 1995), but the light responses of these cells have not been clearly described. Furthermore, a functional segregation of ON-center and OFF-center bipolar cell (also known as "depolarizing" and "hy-

Received Dec. 28, 1999; revised March 27, 2000; accepted April 7, 2000.

This work was supported by National Institutes of Health Grants EY 04446 and EY 02520 and grants from the Retina Research Foundation (Houston, TX) and the Research to Prevent Blindness, Inc.

Correspondence should be addressed to Dr. Samuel M. Wu, Cullen Eye Institute, Baylor College of Medicine, 6565 Fannin Street, NC-205, Houston, TX 77030. E-mail:swu@bcm.tmc.edu.

Copyright (C) 2000 Society for Neuroscience $0270-6474 / 00 / 204462-09 \$ 15.00 / 0$ perpolarizing" bipolar cells, or DBCs and $\mathrm{HBCs}$, respectively) inputs to the IPL has been well established across many species; the on-center cells synapse at the proximal levels of the IPL (sublamina B), and the off-center cells synapse at the distal levels of the IPL (sublamina A) (Famiglietti and Kolb, 1976; Nelson et al., 1978).

Bipolar cells of the tiger salamander retina have been shown previously to vary greatly with respect to light response sensitivity and kinetics (Hensley et al., 1993; Yang and Wu, 1997), but cell morphology was not routinely examined in these experiments. In this study, we investigated the light responses of morphologically identified bipolar cells under voltage-clamp conditions in salamander retinal slices. The axon terminal morphology of these cells was compared with a number of light response characteristics: the relative strength of rod and cone inputs, the polarity, amplitude, and kinetics of excitatory and inhibitory light responses, and the spontaneous EPSCs and IPSCs (sEPSCs and sIPSCs). On the basis of this comparison of axon terminal morphology and light response characteristics, 12 distinct types of bipolar cells were identified, each of which transmits a different set of light response qualities to the third-order retinal neurons by synapses made at different levels of the IPL.

\section{MATERIALS AND METHODS}

Larval tiger salamanders (Ambystoma tigrinum) purchased from Charles D. Sullivan (Nashville, TN) and Kons Scientific (Germantown, WI) were used in this study. The procedures of dissection, retinal slicing, and recording were described in previous publications (Werblin, 1978; Wu, 1987). Salamanders were dark adapted for $3 \mathrm{hr}$ before dissection, and dissection and electrode placement were performed under dim red light. Oxygenated Ringer's solution was introduced continuously to the superfusion chamber, and the control Ringer's solution contained $108 \mathrm{~mm}$ 
A.

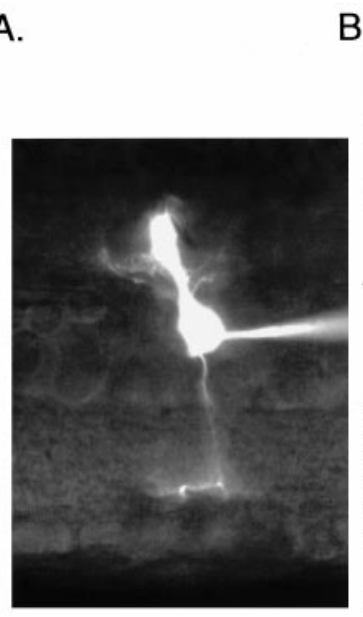

B.

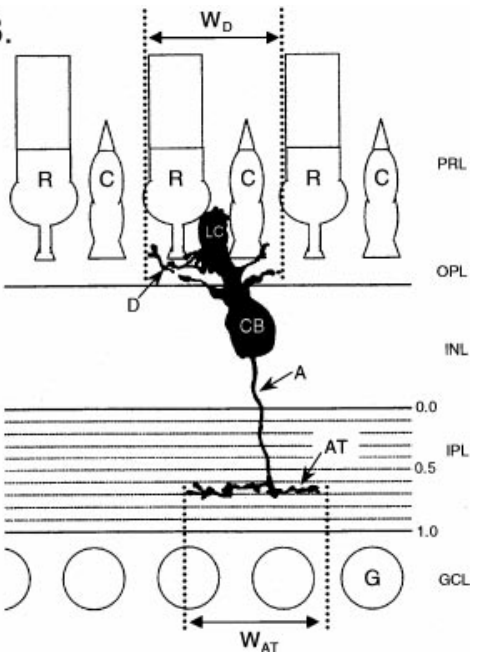

Figure 1. A, A fluorescence photograph of a bipolar cell in a retinal slice filled with Lucifer yellow. $B$, A sketch made while viewing the same cell at different focal planes. Depth within the IPL was characterized in inner plexiform layer units, with the $I N L$ margin corresponding to $0.0 \mathrm{IU}$ and the ganglion cell margin to $1.0 \mathrm{IU}$. $A$, Axon; $A T$, axon terminal; $C$, cone; $C B$, cell body; $D$, dendrite; $G$, ganglion; $G C L$, ganglion cell layer; $I N L$, inner nuclear layer; $L C$, Landolt club; $O P L$, outer plexiform layer; $P R L$, photoreceptor layer; $R$, rod; $W_{\mathrm{AT}}$, axon terminal field width; $W_{D}$, dendritic field width.

$\mathrm{NaCl}, 2.5 \mathrm{~mm} \mathrm{KCl}, 1.2 \mathrm{~mm} \mathrm{MgCl}_{2}, 2 \mathrm{~mm} \mathrm{CaCl}_{2}$, and $5 \mathrm{~mm}$ HEPES, adjusted to $\mathrm{pH}$ 7.7. All chemicals were dissolved in control Ringer's solution. A photostimulator was used to deliver light spots $(500-600 \mu \mathrm{m}$ in diameter) to the retina via the epi-illuminator of the microscope. The intensity of unattenuated $(\log I=0) 500 \mathrm{~nm}$ light $(10 \mathrm{~nm}$ bandwidth $)$, measured with a radiometric detector (United Detector Technology, Santa Monica, CA), was $2.05 \times 10^{7}$ photons $\mu \mathrm{m}^{-2} \cdot \mathrm{sec}^{-1}$.

Voltage-clamp recordings were made with an Axopatch 200A amplifier connected to a DigiData 1200 interface and pClamp 6.1 software (Axon Instruments, Foster City, CA). Patch electrodes of $5 \mathrm{M} \Omega$ tip resistance when filled with internal solution containing $118 \mathrm{~mm}$ Cs methanesulfonate, $12 \mathrm{~mm} \mathrm{CsCl}, 5 \mathrm{~mm}$ EGTA, $0.5 \mathrm{~mm} \mathrm{CaCl}_{2}$, 4 mM ATP, $0.3 \mathrm{~mm}$ GTP, $10 \mathrm{~mm}$ Tris, and $0.8 \mathrm{~mm}$ Lucifer yellow, adjusted to $\mathrm{pH} 7.2$ with $\mathrm{CsOH}$, were made with Narishige or Kopf patch electrode pullers. The chloride equilibrium potential $\left(E_{\mathrm{Cl}}\right)$ with this internal solution was approximately $-60 \mathrm{mV}$. Estimates of the liquid junction potential at the tip of the patch electrode before seal formation varied from -9.2 to $-9.6 \mathrm{mV}$. For simplicity, we corrected all holding potentials in this paper by $10 \mathrm{mV}$.

Cell morphology was visualized via the use of Lucifer yellow fluorescence, and morphometry was performed with the aid of an eyepiece micrometer. The level at which axonal processes stratified in the IPL was characterized by the distance from the processes to the distal margin of the IPL. This distance was expressed in inner plexiform layer units (IU), in which the thickness of the entire IPL was defined as 1.0 IU (see Fig. $1 B)$. We selected for bipolar cells with somas situated beneath the surface of the slice. These cells usually had relatively intact axon terminals, but in cases in which the axons were severed or the axon terminals were badly deformed, the data were discarded. The anatomical data presented (see Figs. 2, 3) include data from similar patch-clamp experiments not described in this paper.

\section{RESULTS}

\section{Morphological diversity of bipolar cells in the salamander retina}

Figure 1 shows a fluorescence photograph of a bipolar cell in a retinal slice (Fig. $1 A$ ) and a sketch made while viewing the same cell at different focal planes (Fig. $1 B$ ). Typical bipolar cell features (labeled in Fig. $1 B$ ) include a soma (cell body) centered in the distal half of the inner nuclear layer, a Landolt club extending into the outer nuclear layer, dendrites branching in the outer

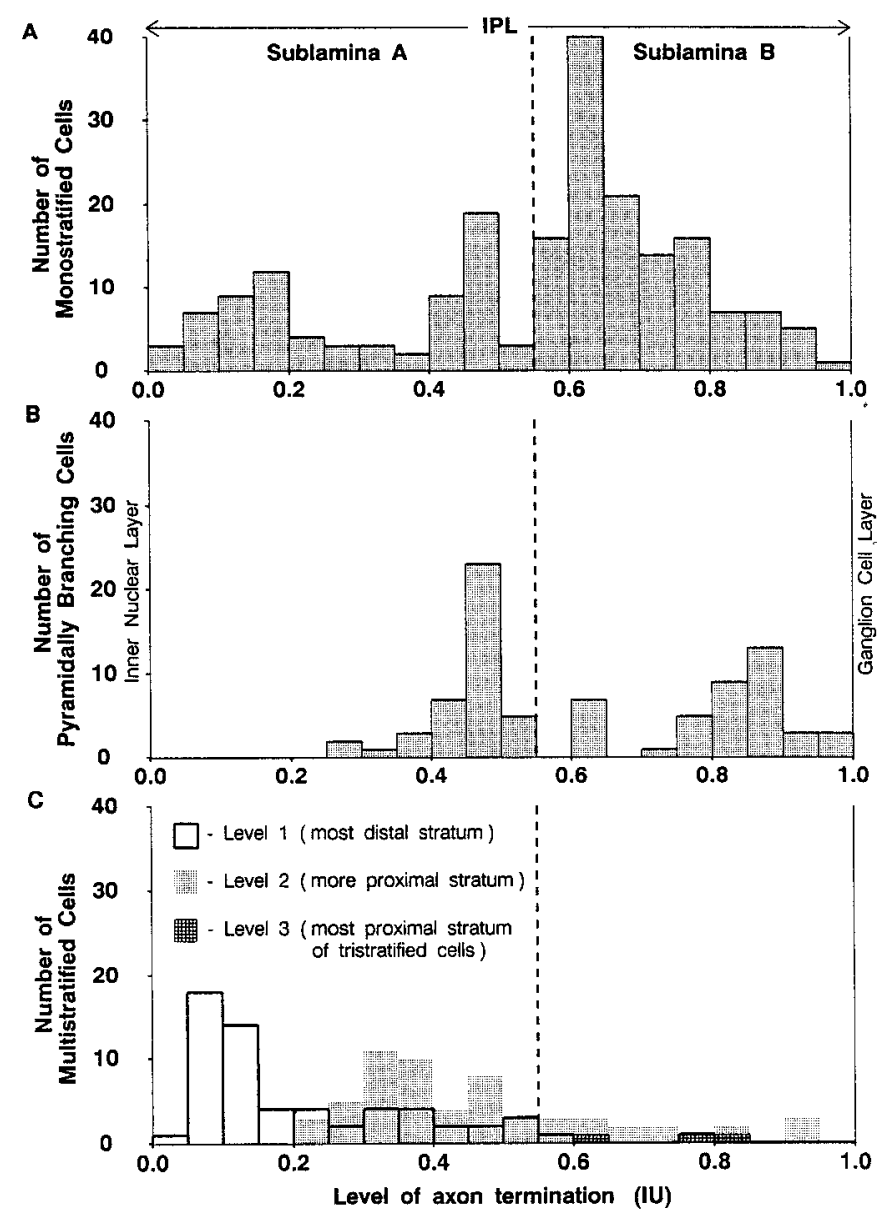

Figure 2. Frequency histograms for the levels of bipolar cell axon terminal ramification within the IPL. $A$, Cells with axon terminals ramifying in a single stratum (monostratified). $B$, Cells with pyramidally branching axon terminals. $C$, Cells with axon terminals ramifying in more than one strata (multistratified). Histograms were plotted against the level of axon terminal endings in inner plexiform layer units (defined in Fig. $1 B$ and Materials and Methods) with a bin width of 0.05 IU. On the basis of light responses (see Fig. 5) and dendritic glutamate responses (Maple and $\mathrm{Wu}$, 1996), sublamina A is defined as $0.0-0.55 \mathrm{IU}$, and sublamina B is defined as $0.55-1.0 \mathrm{IU}$.

plexiform layer, and an axon with terminal processes ramifying laterally within the IPL. The bipolar cell of Figure 1 is an example of what we termed a "monostratified" cell, i.e., a cell with axon terminals that ramified in a very planar manner within a single narrow level of the IPL. Although a majority (59\%) of the 343 cells studied were monostratified, two other classes of axon terminal morphology were observed. Some bipolar cells (24\%) had "pyramidally branching" axons; i.e., although their axonal processes terminated at a narrow level within the IPL, they began branching at more distal levels of the IPL (see Fig. 5, cell types 5, $8,12)$. In addition, some cells were "multistratified"; i.e., their axon terminals were stratified at two or three distinct levels within the IPL (e.g., see Fig. 5, cell types 3, 4, 6, 11). Bistratified and tristratified cells accounted for 17 and $1 \%$, respectively, of the bipolar cells studied.

The spatial distribution of the bipolar cell axon terminals within the IPL is summarized in Figure 2, which shows frequency histograms for the level of ramification (or termination in the case of pyramidally branching cells) for each of these three general morphological classes of axon terminals. Monostratified cells ap- 

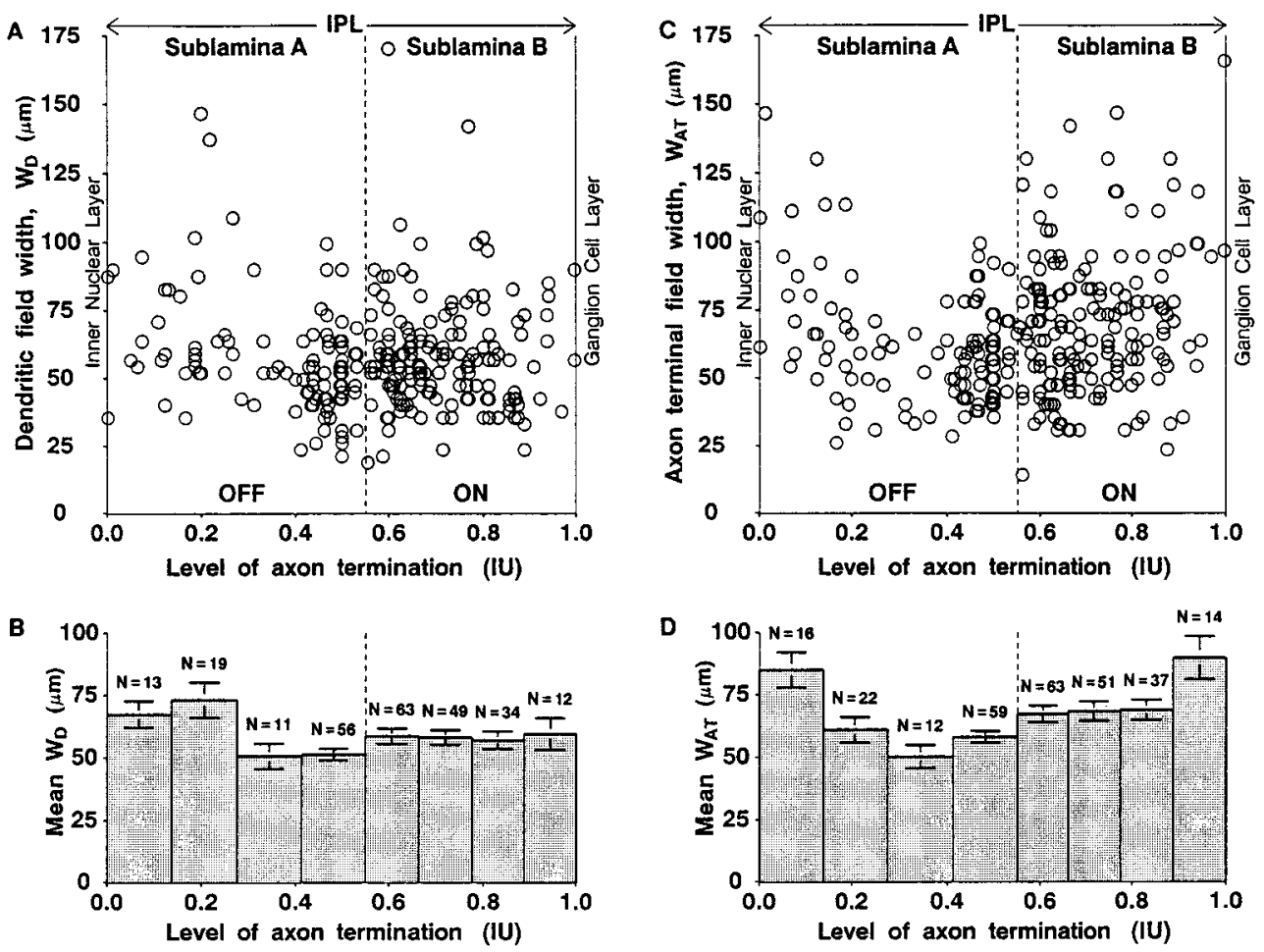

Figure 3. $A, C$, Scatter plots of $W_{D}$ (defined in Fig. $1 B ; A)$ and $W_{\mathrm{AT}}(C)$ against the level of the axon terminal ramification in the IPL (in inner plexiform layer units). $B, D$, The mean ( $\pm \mathrm{SE}) W_{D}$ and $W_{\mathrm{AT}}$ are shown in $B$ and $D$, respectively.

peared to terminate continuously throughout the depth of the IPL, but the peaks in Figure $2 A$ suggest a nonuniform distribution of axon termination in the IPL. The distribution for pyramidally branching cells (Fig. $2 B$ ) was also decidedly nonuniform, with peaks near 0.5 and 0.85 IU (IU is defined in Fig. $1 B$ and Materials and Methods). The multistratified cells (Fig. 2C) ramified mostly in sublamina A [defined as $0-0.55$ IU, on the basis of dendritic glutamate responses (Maple and Wu, 1996) and light responses discussed in this paper]. Seventy-two percent of bistratified bipolar cells ramified exclusively in sublamina A, whereas $<4 \%$ of the bistratified cells ramified exclusively in sublamina B (0.55-1.0 IU). All three tristratified cells observed had two levels of ramification in sublamina $\mathrm{A}$ and one in sublamina B. It is important to note that the distributions presented in Figure 2 could be influenced by sampling bias, so they do not necessarily reflect the actual relative frequencies of different bipolar cell types in the salamander retina.

The widths of the dendritic field $\left(W_{D}\right)$ and axon terminal field $\left(W_{\mathrm{AT}}\right)$, as defined in Figure $1 B$, were also characterized for most cells, and these data are presented as scatter plots in Figure 3, $A$ and $C$, respectively. (For simplicity, the data for multistratified cells are not included in Fig. 3.) The dendritic and axon terminal field widths were both highly variable, even for cells with otherwise similar morphology. There was a tendency, however, for $W_{\mathrm{AT}}$ to be significantly larger for cells ramifying near either margin of the IPL than for cells ramifying more centrally, as is evident in the mean width histogram of Figure $3 D$. Such a striking pattern was not observed for the dendritic field widths (Fig. 3C), but there was a significant tendency for $W_{D}$ to be larger for cells ramifying in the distal half of sublamina $A$ than for those terminating in the proximal half of sublamina A. Averaged over all cells, the mean $W_{D}( \pm \mathrm{SD})$ was $58 \pm 21 \mu \mathrm{m}$, and the mean $W_{\mathrm{AT}}$ was $67 \pm 25 \mu \mathrm{m}$.

A most conservative interpretation of the data in Figure 2 is that the salamander retina possesses at least nine types of bipolar cells (four monostratified types, two pyramidally branching types, two bistratified types, and one tristratified type). The data suggest, however, that more types than these exist. In slices with good structure it is easy to distinguish a difference between monostratified cells that ramify at 0.05 and $0.20 \mathrm{IU}$, for instance, so it would seem likely that these represent different cell types. On the other hand, in the region of $0.0-0.3 \mathrm{IU}$, there is only a single peak in the frequency histogram of Figure $2 A$, so from axon morphology alone, it is not clear just how many different types of bipolar cells may ramify in this region. The dendritic and axon terminal field widths do not aid much in distinguishing cell types; although there is a significant difference in mean axon terminal field width for cells ramifying near $0.05 \mathrm{IU}$ versus those terminating near $0.20 \mathrm{IU}$, the widths are not clustered in any way suggesting distinctly different cell types.

\section{Photoreceptor inputs to bipolar cells}

Figure 4 compares light responses of a DBC with responses of an HBC. In both cases the photoreceptor inputs were isolated by holding the cell at $E_{\mathrm{Cl}}$ (thus eliminating any inhibitory currents that might be generated at chloride-mediated synapses from amacrine cells and interplexiform cells). Under these conditions the $\mathrm{DBCs}$, which give rise to the ON pathway of the visual system, displayed inward current responses $\left(\Delta I_{C}\right.$; Fig. $4 A$, the lightevoked cation current,). In contrast, the $\mathrm{HBCs}$, which mediate the OFF pathway, exhibited an outward $\Delta I_{C}$ (Fig. $4 B$ ). HBCs could also be distinguished from DBCs on the basis of the presence of spontaneous sEPSCs (Maple et al., 1994; Wu and Maple, 1998), as illustrated in the Figure $4 B$ inset. In darkness the HBCs displayed a very high frequency of sEPSCs, which are responsible for the prominent current noise visible in the records of Figure $4 B$. The sEPSCs decreased in frequency during a light stimulus, and this is reflected in Figure $4 B$ as a decrease of current noise during light stimulation. Although the mean amplitude of the sEPSCs appeared to vary among different HBC subtypes, 
A.
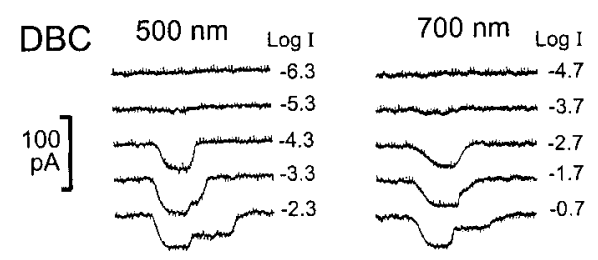

B.
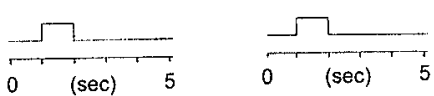

B.

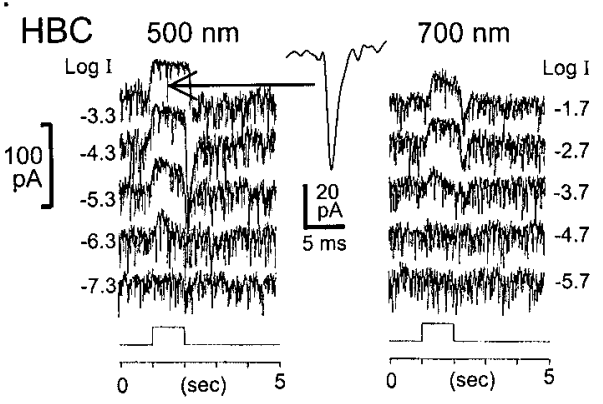

C.

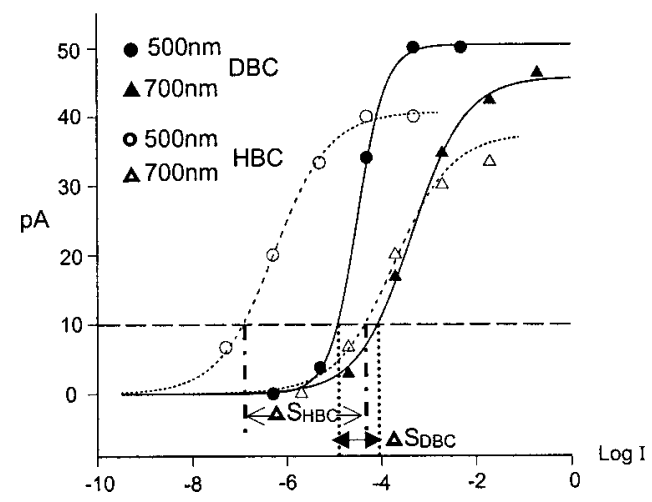

Figure 4. $A, B$, Current responses of a $\operatorname{DBC}(A)$ and an $\operatorname{HBC}(B)$ to 500 and $700 \mathrm{~nm}$ light steps of various intensities (labeled in log units of attenuation on the left of each current trace). $C$, The response-intensity relations for these current responses. For the criterion response of $10 \mathrm{pA}$ marked by the horizontal dashed line, $\Delta S$ for the DBC is 0.81 and for the $\mathrm{HBC}$ is 2.60 . Inset in $B$, One of the sEPSCs that contributed to the very noisy signals observed in this cell.

sEPSCs were observed in all HBCs. On the other hand, sEPSCs were never observed in DBCs, with the exception of two types of multistratified cells that will be discussed below.

Cone photoreceptors in the tiger salamander retina exhibit similar sensitivity to red and green light, but the rod photoreceptors are much more sensitive to green than to red light (Yang and Wu, 1989, 1996). Consequently, the relative strength of rod and cone inputs to bipolar cells could be characterized by comparing response-intensity relations for 500 and $700 \mathrm{~nm}$ light stimuli, as demonstrated in Figure 4. Response-intensity curves for data from a DBC (Fig. $4 A$ ) and an HBC (Fig. $4 B$ ) are shown in Figure $4 C$. Comparing the curves for 500 and $700 \mathrm{~nm}$ stimuli, it is apparent that there is a greater separation of the two curves along the intensity axis for the HBC data (denoted by open symbols) than for the DBC data (denoted by filled symbols), suggesting that this $\mathrm{HBC}$ received stronger rod input than did the DBC. The separation of the curves was quantified by a measure termed the "spectral difference" $(\Delta S)$, defined as $\Delta S=S_{700}-S_{500}$, where $S_{700}$ and $S_{500}$ correspond to intensities of 700 and $500 \mathrm{~nm}$ light that yield responses equal in amplitude, for a small criterion amplitude (Yang and Wu, 1996). Measured at a criterion amplitude of $10 \mathrm{pA}$, as illustrated in Figure $4 C$, the spectral difference was $0.8 \log$ units for the $\mathrm{DBC}$ and $2.6 \log$ units for the HBC. Because $\Delta S$ is $\sim 0.1 \log$ units for cones and $\sim 3.4 \log$ units for rods (Yang and Wu, 1990), we concluded that the DBC of Figure 4 was cone dominated, whereas the HBC was relatively rod dominated. Overall, a wide range of rod and cone dominance was observed both for DBCs $(\Delta S=0.2-2.9)$ and for HBCs $(\Delta S=0.3-3.1)$.

By combining this spectral difference data with data concerning axon terminal morphology, light response polarity, the kinetics of excitatory and inhibitory currents at light onset and offset, and the spontaneous postsynaptic currents, we were able to define 12 different classes of bipolar cells, as depicted in Figure 5A. The levels of axon terminal ramification in the IPL (in inner plexiform layer units), the mean ( \pm SE) values of the spectral difference $(\Delta S)$, and the amplitude of the light-evoked excitatory cation current $\left(\Delta I_{C}\right)$ and inhibitory current $\left(\Delta I_{\mathrm{Cl}}\right.$, the light-evoked chloride current recorded at $0 \mathrm{mV}$, near the reversal potential for photoreceptor inputs) at light onset (ON) and offset (OFF) are given in Figure 5B. (Note that the cells included in these averages constitute a subset of the cells described in Fig. 2, i.e., the subset for which light response data were obtained as described in this paper.) Additionally, the frequency of large sEPSCs and sIPSCs in each class of bipolar cells was estimated on an approximate scale $\left(0\right.$ to $\left.{ }^{* * *}\right)$ in Figure $5 B$. The 12 classes defined here represent types that were clearly distinguishable by two or more of the parameters listed in Figure $5 B$. These parameters will now be discussed with respect to how visual signals are mapped in the IPL.

\section{The segregation of ON-center and OFF-center bipolar cell (DBC and $\mathrm{HBC}$ ) outputs in the IPL}

Among the bipolar cells that ramified exclusively in sublamina A of the IPL (Fig. 5, types 1-5), all exhibited outward light-evoked current $\left(\Delta I_{C}\right)$ near $E_{\mathrm{Cl}}$; i.e., they were HBCs. Likewise, all cells that ramified exclusively in sublamina B (types 7-10) were DBCs, displaying inward $\Delta I_{C}$ near $E_{\mathrm{Cl} \text {. }}$ These results are in agreement with the general observation that the OFF-center and ON-center pathways are segregated into sublamina A and sublamina B, respectively (Famiglietti and Kolb, 1976; Nelson et al., 1978). However, we observed three types of bipolar cells that ramified in both sublamina A and sublamina B. One of these was a class of pyramidally branching cell (type 12), with axonal processes that began branching in sublamina $\mathrm{A}$ but terminated at a proximal level of sublamina B (0.8-0.9 IU). These cells appeared to be purely DBCs, on the basis of an inward $\Delta I_{C}$ at $E_{\mathrm{Cl}}$ and the absence of sEPSCs. Another class of cell (type 11) that stratified in both sublamina A and sublamina B appeared to be a hybrid, possessing both ON-center (sign-reversing) and OFF-center (sign-preserving) cationic conductance mechanisms at photoreceptor synapses. These cells, which (like HBCs) exhibited sEPSCs, also displayed a net inward $\Delta I_{C}$ at $E_{\mathrm{Cl}}$, (like DBCs). Curiously, in previous experiments conducted in bright light, cells with this distinctive morphology exhibited a cationic conductance increase in response to dendritic application of glutamate (Maple and $\mathrm{Wu}, 1996)$; furthermore, one such cell was studied in an experiment in which the rod network was depolarized with a second patch electrode, and this stimulus also elicited a cationic conductance increase in the bipolar cell, as would be expected for 


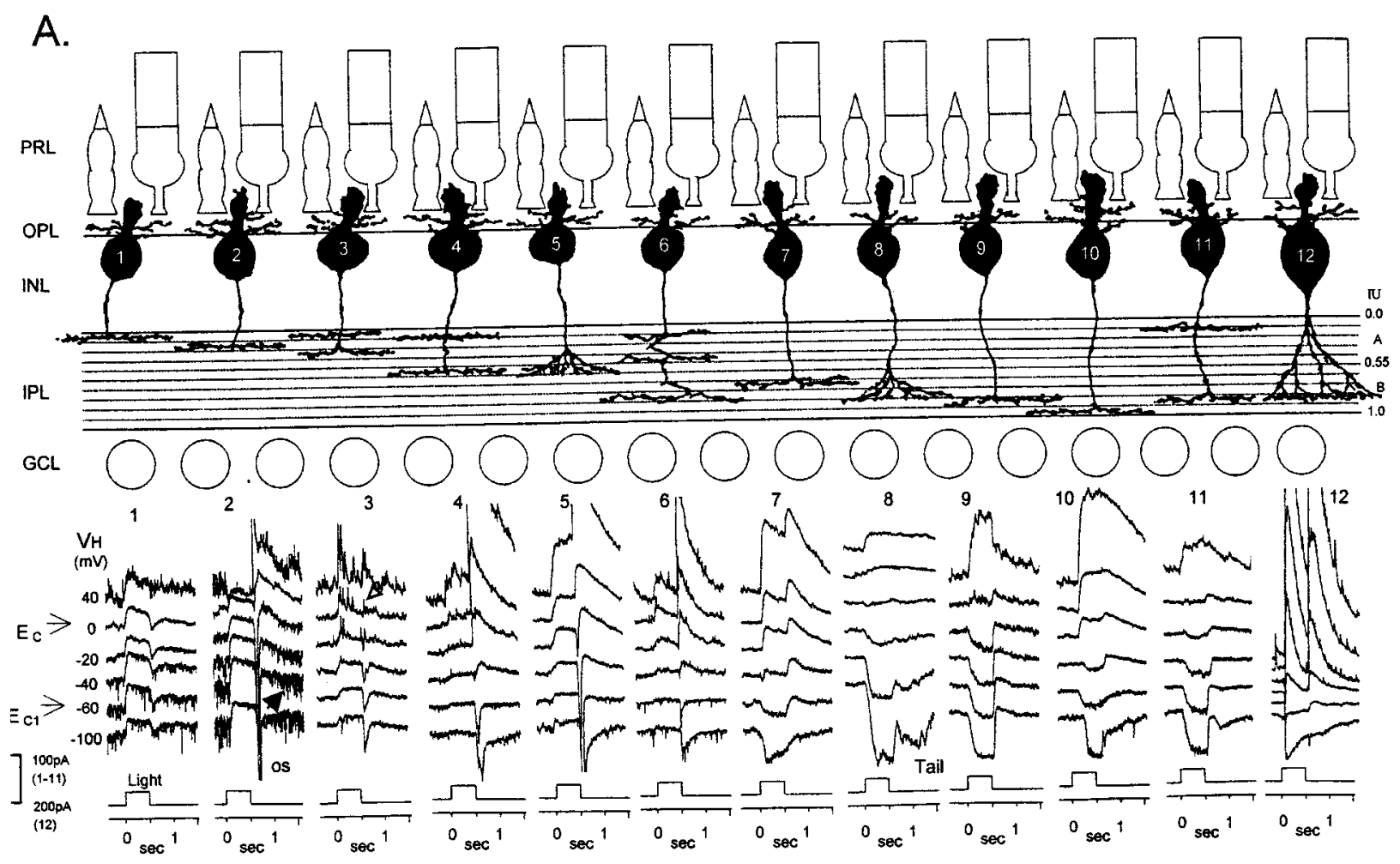

B.

\begin{tabular}{|c|c|c|c|c|c|c|c|c|c|c|c|c|}
\hline Cell Type & 1 & 2 & 3 & 4 & 5 & 6 & 7 & 8 & 9 & 10 & 11 & 12 \\
\hline $\begin{array}{l}\text { Level of } 1 \text { st } \\
\text { axon term- 2nd } \\
\text { ination (IU) 3rd }\end{array}$ & .00 .15 & $.15-30$ & $\begin{array}{l}.05-0.15 \\
.25-.40\end{array}$ & $\begin{array}{l}.10-.35 \\
.45-.55\end{array}$ & $.35-.55$ & $\begin{array}{l}.05-.15 \\
.30-.40 \\
.60-.85 \\
\end{array}$ & $.55-.70$ & $.70-.80$ & $.80-.90$ & $.90-1.0$ & $\begin{array}{l}.10-20 \\
.80-.90\end{array}$ & $.80-.90$ \\
\hline $\begin{array}{c}\Delta S_{ \pm S . E .} \\
(\mathrm{N})\end{array}$ & $\begin{array}{c}2.8 \pm 0.2 \\
(7)\end{array}$ & $\begin{array}{c}2.2 \pm 0.7 \\
(12)\end{array}$ & \begin{tabular}{|c|}
$1.7 \pm 0.3$ \\
$(8)$ \\
\end{tabular} & $\begin{array}{c}0.9+0.2 \\
(5)\end{array}$ & $\begin{array}{c}0.4 \pm 0.3 \\
(6)\end{array}$ & $\begin{array}{c}1.1 \pm 0.2 \\
(2)\end{array}$ & \begin{tabular}{|c|}
$0.6 \pm 0.4$ \\
$(6)$
\end{tabular} & $\begin{array}{c}1.8 \pm 0.5 \\
(13)\end{array}$ & $\begin{array}{c}0.9 \pm 0.3 \\
(4)\end{array}$ & $\begin{array}{c}2.2 \pm 0.5 \\
(6) \\
\end{array}$ & $\begin{array}{l}1.2 \pm 0.4 \\
(2)\end{array}$ & $\begin{array}{c}1.8 \pm 0.5 \\
(3)\end{array}$ \\
\hline $\begin{array}{l}\Delta l C O N \pm S . E . \\
\text { in } \mathrm{AA}(\mathrm{N})\end{array}$ & $\begin{array}{c}+70 \pm 9 \\
(8)\end{array}$ & $\begin{array}{c}+53 \pm 5 \\
(14)\end{array}$ & $\begin{array}{c}+35+5 \\
(10) \\
\end{array}$ & $\begin{array}{c}+12+3 \\
(6)\end{array}$ & $\begin{array}{c}+41 \pm 7 \\
(7)\end{array}$ & $\begin{array}{c}+23 \pm 7 \\
(2)\end{array}$ & \begin{tabular}{|c|}
$-38 \pm 4$ \\
$(7)$ \\
\end{tabular} & $\begin{array}{r}-50 \pm 7 \\
(13) \\
\end{array}$ & $\begin{array}{c}-74+8 \\
(4)\end{array}$ & $\begin{array}{l}-67 \pm 9 \\
(8)\end{array}$ & $\begin{array}{l}-83 \pm 6 \\
(2) \\
\end{array}$ & $\begin{array}{c}-76 \pm 11 \\
(3) \\
\end{array}$ \\
\hline 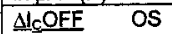 & $-.31 \pm .23$ & $-4.9 \pm 1.3$ & $-3.8 \pm 1.0$ & $-4.8 \pm t .1$ & $-14.5 \pm 2.5$ & $-2.8 \pm .7$ & $-.19 \pm .1$ & $.13 \pm .1$ & $-.09 \pm .04$ & $.35 \pm .23$ & $-.02 \pm .14$ & $.63 \pm .02$ \\
\hline$\Delta \mathrm{l}_{\mathrm{C}} \overline{\mathrm{ON}}$ & $.57 \pm .04$ & $.50 \pm .09$ & $.29 \pm .08$ & $.13 \pm .08$ & $.49 \pm .07$ & $.19 \pm .13$ & $.06 \pm .04$ & $.43 \pm .09$ & $.01 \pm .01$ & $.38 \pm .07$ & $.09 \pm .06$ & $.03 \pm .02$ \\
\hline$\Delta \mathrm{l}_{c} \mathrm{ON} / \Delta \mathrm{l}_{\mathrm{c}} \mathrm{ON}$ & $.68 \pm .07$ & $.63 \pm .09$ & $1.04 \pm .24$ & $1.8 \pm .5$ & $1.5 \pm .6$ & $3.7 \pm .1$ & $-2.2+2$ & $-.91 \pm .31$ & $-.22 \pm .05$ & $-1.18 \pm .26$ & $-.01 \pm .01$ & $-6.3 \pm .3$ \\
\hline$\Delta \mathrm{I}_{c} \mathrm{OFF} / \Delta \mathrm{I}_{c} \mathrm{ON}$ & $-.18 \pm .06$ & $-.96 \pm .22$ & $-.78 \pm .15$ & $-13.2+2.9$ & $-2.8 \pm .8$ & $-7.9 \pm .9$ & $.8 \pm .2$ & $.28 \pm .07$ & $.26 \pm .07$ & $.31 \pm .13$ & $.23 \pm .07$ & $4.0 \pm .1$ \\
\hline \begin{tabular}{|l} 
SEPSCS \\
\end{tabular} & $* * *$ & $* * * *$ & $*$ & 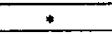 & $* *$ & $* *$ & 0 & 0 & 0 & 0 & $*$ & 0 \\
\hline SIPSCS & * & * & $* * *$ & $* * *$ & 0 & $* * *$ & $* *$ & $*$ & $* *$ & 0 & $*$ & $* *$ \\
\hline
\end{tabular}
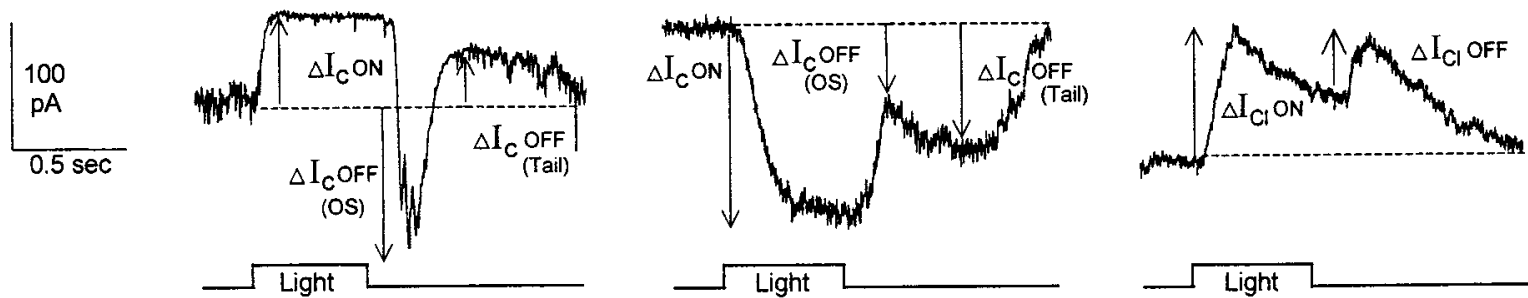

Figure 5. A, Morphology (sketches of Lucifer yellow-filled cells in retinal slices; top row) and light-evoked current responses (to a 500 nm stimulus of $-1.3 \log$ unit intensity; bottom row) recorded under voltage-clamp conditions at various holding potentials. For all cells, $E_{C}=0 \mathrm{mV}$ and $E_{\mathrm{Cl}}=-60 \mathrm{mV}$, and thus $\Delta I_{C}$ and sEPSCs were measured at $-60 \mathrm{mV}$, and $\Delta I_{\mathrm{Cl}}$ and sIPSCs were measured at $0 \mathrm{mV}$. Vertical calibration bar (bottom left): $100 \mathrm{pA}$ for type 1-11 bipolar cells; $200 \mathrm{pA}$ for the type 12 bipolar cell. $B$, Top, Summary of the levels of axon terminal ramification in the IPL (in inner plexiform layer units), the average ( \pm SE) values $(N$, number of cells averaged) of the relative spectral difference $(\Delta S)$ and the amplitude (in pA) and polarity $(+$, outward; -, inward) of the light-evoked excitatory current at light onset $\left(\Delta I_{C} \mathrm{ON}\right)$, the ratios of excitatory current response at light offset/onset $\left(\Delta I_{C} \mathrm{OFF} / \Delta I_{C} \mathrm{ON}\right)$ for off overshoot $(O S)$ and tail (Tail) responses, the ratios of light-evoked inhibitory ON and OFF current response/excitatory ON current response $\left(\Delta I_{\mathrm{Cl}} \mathrm{ON} / \Delta I_{C} \mathrm{ON}, \Delta I_{\mathrm{Cl}} \mathrm{OFF} / \Delta I_{C} \mathrm{ON}\right)$, and the approximate frequency $(0$, absent; *, low; **, medium; and ***, high) of sEPSCs and sIPSCs for the 12 classes of bipolar cells. Bottom, Illustrations of how $\Delta I_{C} \mathrm{ON}, \Delta I_{C} \mathrm{OFF}(\mathrm{OS}), \Delta I_{C} \mathrm{OFF}(\mathrm{Tail}), \Delta I_{\mathrm{Cl}} \mathrm{ON}$, and $\Delta I_{\mathrm{Cl}} \mathrm{OFF}$ of the $\mathrm{HBC}$ and the DBC were measured. For responses that had no cationic current tail of the same polarity as $\Delta I_{C} \mathrm{ON}, \Delta I_{C} \mathrm{OFF}$ (Tail) was assigned a value of zero. The values of $\Delta I_{C} \mathrm{OFF}(\mathrm{OS}), \Delta I_{C} \mathrm{OFF}\left(\right.$ Tail), $\Delta I_{\mathrm{Cl}} \mathrm{ON}$, and $\Delta I_{\mathrm{Cl}} \mathrm{OFF}$ were normalized relative to the value of $\Delta I_{C} \mathrm{ON}$ before averaging. 
an HBC [our unpublished observation from experiments described in Maple et al. (1994)]. It is not clear why these cells appeared to be DBCs in some experiments and HBCs in others, but it could conceivably be related to the different states of light adaptation in these experiments. A type of tristratified cell (type 6) also appeared to possess both ON and OFF conductance mechanisms. These cells normally appeared to be HBCs, with sEPSCs and an outward $\Delta I_{C}$ at $E_{\mathrm{Cl}}$, but in the presence of $100 \mu \mathrm{M}$ picrotoxin the light responses of these cells were converted to an inward (DBC-like) current (data not shown). Thus, it seems there may be a perfect correlation between the sign of photoreceptor inputs received by bipolar cells and the level(s) at which the bipolar cells' axonal processes terminate in the IPL; cells with processes terminating exclusively in sublamina A are excited by darkness (OFF-center), cells with axons terminating exclusively in sublamina $\mathrm{B}$ are excited by light (ON-center), and cells with axon terminations in both sublamina $\mathrm{A}$ and sublamina $\mathrm{B}$ receive both ON-center and OFF-center inputs.

\section{Gradients of rod and cone dominance in the IPL}

The spectral difference data presented in Figure 5 show a general trend for rod-dominated bipolar cells to ramify near the margins of the IPL and for cone-dominated cells to ramify more centrally in the IPL. This correlation was particularly strong for the HBCs, with the most rod-dominated cells (types 1 and 2) being monostratified in the distal half of sublamina $\mathrm{A}\left(\mathrm{sA}_{1}, 0.0-0.3 \mathrm{IU}\right)$ and the most cone-dominated cells (type 5) being monostratified or pyramidally branching within the proximal half of sublamina $\mathrm{A}$ ( $\left.\mathrm{sA}_{2}, 0.3-0.55 \mathrm{IU}\right)$. Even within $\mathrm{sA}_{1}$ a gradient of rod-cone dominance was observed, with the cells ramifying in the distal half of $\mathrm{sA}_{1}$ (type 1 ) being the most rod dominated of all bipolar cells observed and with cells ramifying in the proximal half of $\mathrm{sA}_{1}$ (type 2) being slightly less rod dominated. Cells that were bistratified within sublamina A displayed intermediate values of $\Delta S$, but these could still be divided into two different classes, on the basis of anatomy and spectral sensitivity. The bistratified HBCs exhibited a wide range of axon terminal morphologies, but spectrally they fell into two groups, which also differed consistently with respect to their more proximal level of ramification. Type 4 cells, with a proximal stratum at a depth of $0.45-0.55$ IU, were more cone dominated than type 3 cells, whose most proximal level of ramification was at $0.25-0.40 \mathrm{IU}$.

A similar, but less strict, gradient of rod and cone influence was observed in sublamina B of the IPL. Following a margin to center organization of rod and cone dominance, the most proximally ramifying DBCs (type 10; 0.9-1.0 IU) were rod dominated, the most centrally ramifying DBCs (type 7; 0.55-0.7 IU) were cone dominated, and cells ramifying at intermediate levels were more mixed (types 8 and 9; 0.7-0.9 IU). On the other hand, the mixed cells fell into two different classes that received more or less rod input (types 8 and 9, respectively), and among these there was no simple correlation between $\Delta S$ and the level of ramification. It seems that rod and cone information is not segregated as simply for the ON-center pathways of the retina as it is for the OFFcenter pathways.

The kinetics of the photoreceptor inputs at light offset was also consistent with these gradients of rod and cone dominance in the IPL. Cone photoreceptors rapidly depolarize to a steady-state dark potential at the cessation of a light stimulus, whereas rod photoreceptors depolarize more slowly, taking seconds to reach a steady-state potential after a bright stimulus (Yang and $\mathrm{Wu}$, 1996). This was reflected in the photoreceptor component of bipolar cell light responses, as visible in Figure 5 for the traces at $-60 \mathrm{mV}\left(E_{\mathrm{Cl}}\right)$. At light offset the responses of cone-dominated cells (those with a small $\Delta S$ ) were dominated by a rapidly developing, strongly transient inward current (in the case of HBCs) or a slightly less rapidly developing, mildly transient outward current (in the case of DBCs). For HBCs this transient tended to shoot beyond the prestimulus dark current level, and the size of this overshoot $\left[\Delta I_{C} \mathrm{OFF}(\mathrm{OS})\right.$ in Figure 5, relative to the size of the response to light onset] was negatively correlated with $\Delta S$. The responses of rod-dominated cells (those with a large $\Delta S$ ), on the other hand, were dominated by a slowly developing inward current (in the case of HBCs) or outward current (in the case of DBCs). The size of this slow-current tail $\left[\Delta I_{C} \mathrm{OFF}\right.$ (Tail) in Figure 5 , given relative to the response at light onset] was positively correlated with $\Delta S$ (with the exception of the type 5 conedominated HBCs, which, as discussed below, displayed a sizable tail). These observations are consistent with a general tendency of cone-dominated bipolar cells to ramify more centrally in the IPL than rod-dominated bipolar cells.

Rod- and cone-dominated HBCs could also be distinguished by characteristics of the sEPSCs associated with their photoreceptor inputs (Maple et al., 1994; Wu and Maple, 1998). Roddominated HBCs (types 1 and 2) were readily identified by the presence of large-amplitude sEPSCs. sEPSCs were also observed in the more cone-dominated HBCs (types 3-6), but they appeared to be much smaller in mean amplitude. Quantitative analysis of the sEPSCs in HBCs is not a simple matter, because they vary tremendously in amplitude, the amplitude distributions are highly skewed toward the baseline noise, and the distributions do not have peaks that stand out from the baseline noise, even under very low-noise conditions (Maple et al., 1994); furthermore, there is much superposition of the sEPSCs under the dark-adapted conditions described in this paper. For these reasons, the issue of sEPSC amplitude will not be quantitatively addressed here. Instead, an approximate scale ( 0 to $* * *)$ was used in Figure $5 B$. We would like to emphasize that the rod-dominated HBCs (types 1 and 2) could be easily and reliably distinguished from more cone-dominated HBCs (types 3-6) on the basis of qualitative examination of the noise associated with $\Delta I_{C}$. As is visible in the traces of Figure 5, the rod-dominated HBCs exhibited much more noise (at $E_{\mathrm{Cl}}$ ) and some much larger sEPSCs (of up to $1 \mathrm{nS}$ peak conductance) than did the cone-dominated HBCs. This difference points to a functional segregation of rod and cone information in the IPL.

\section{Inhibitory inputs to bipolar cells}

When held at $0 \mathrm{mV}$ (near $E_{C}$, the reversal potential for cation currents generated at photoreceptor synapses), most bipolar cells displayed outward current responses at light onset and/or light offset. In cases in which these inhibitory responses were very transient (e.g., Fig. 5, the onset response of cell 12 or the offset response of cell 5), they clearly reversed near $E_{\mathrm{Cl}}$, and it is likely that they were generated by a chloride conductance increase. It was more difficult to characterize the $I-V$ properties of more sustained inhibitory inputs, because these were masked by photoreceptor inputs at holding potentials away from $E_{C}$. Nevertheless, the overall $I-V$ characteristics of the light responses suggested that a sustained chloride conductance increase contributed to the onset response of many bipolar cells. Consider, for instance, the responses to light onset for HBC types 1, 2, and 5 in Figure 5. The responses of type 2 cells reversed near $+20 \mathrm{mV}$, considerably positive to the reversal potential for the sEPSCs, 
which reversed near $0 \mathrm{mV}$ (as do glutamate-activated currents in HBCs). This is understandable if the light-induced cationic conductance decrease occurring at photoreceptor synapses was accompanied by a smaller conductance increase to an ion with a negative equilibrium potential (for instance, a chloride conductance increase at amacrine cell synapses). In the case of type 1 HBCs the light responses did not reverse at all, and that is consistent with a chloride conductance increase that was comparable in magnitude with the cationic conductance decrease at photoreceptor synapses. Finally, for type $5 \mathrm{HBCs}$ the light responses did not reverse but became larger with increasingly positive potentials, and this is consistent with a chloride conductance increase that was larger than the accompanying cationic conductance decrease. Because DBCs undergo a cationic conductance increase at light onset, a simultaneous chloride conductance increase would be expected to make the light response reverse negative to $E_{C}$ in these cells, and this was, in fact, observed. Where the reversal potential of DBC light responses differed from $E_{C}$, it was always negative to $E_{C}$ (and positive to $E_{\mathrm{Cl}}$ ).

Figure $5 B$, top, summarizes the relative strengths of the inferred chloride conductance increases at light onset $\left(\Delta I_{\mathrm{Cl}} \mathrm{ON}\right)$ and light offset $\left(\Delta I_{\mathrm{Cl}} \mathrm{OFF}\right)$ for each of the 12 classes of bipolar cells we have defined. Among the six classes of HBCs, the mean values of both $\Delta I_{\mathrm{Cl}} \mathrm{ON}$ and $\Delta I_{\mathrm{Cl}} \mathrm{OFF}$ (relative to the magnitude of $\Delta I_{\mathrm{Cl}} \mathrm{ON}$ ) were negatively correlated with $\Delta S$; i.e., the inhibition at both light onset and light offset was stronger for the conedominated cells than for the rod-dominated cells. Among the $\mathrm{DBCs}$, there was not, in general, a strong correlation between either $\Delta I_{\mathrm{Cl}} \mathrm{ON}$ or $\Delta I_{\mathrm{Cl}} \mathrm{OFF}$ and $\Delta S$, but both $\mathrm{ON}$ and OFF inhibitions were stronger for the most cone-dominated cells (type 7) than for the most rod-dominated cells (type 10). Overall, the strength of these inhibitory inputs appeared to be more closely related to axon morphology than to the value of $\Delta S$, per se. The relative magnitude of $\Delta I_{\mathrm{Cl}} \mathrm{ON}$ tended to be largest among bipolar cell types 4-7 and 12, all cells with ramifications near a central region (0.4-0.7 IU) of the IPL. Similarly, $\Delta I_{\mathrm{Cl}} \mathrm{OFF}$ was largest in cells with ramifications in sublamina $\mathrm{A}_{2}(0.3-0.55 \mathrm{IU})$.

A portion of the inhibition received by bipolar cells was mediated by sIPSCs, which are thought to be generated at synapses from glycinergic amacrine and interplexiform cells (Maple and $\mathrm{Wu}, 1998)$. Most bipolar cells exhibited some sIPSCs, but, overall, this inhibition accounted for only a small fraction of the total chloride current elicited by light stimuli. This type of inhibition was particularly strong, however, in the type 3 bistratified HBCs, which displayed strong bursts of sIPSCs both at light onset and offset. On the other end of the spectrum, very few or no sIPSCs were observed in type $5 \mathrm{HBCs}$ and type $10 \mathrm{DBCs}$. Type 7 DBCs varied greatly with respect to sIPSC activity; in some the sIPSCs contributed greatly to $\Delta I_{\mathrm{Cl}} \mathrm{OFF}$, and in others very few IPSCs were observed. Further study of inhibitory inputs to bipolar cells may lead to a division of type 7 cells into different subtypes.

\section{DISCUSSION}

\section{ON-center and OFF-center channels}

In agreement with previous studies of dendritic glutamate responses (Maple and Wu, 1996), the light responses described here indicate that in the salamander retina, OFF-center bipolar cells make output synapses in the most distal $55 \%$ of the IPL (sublamina A), whereas ON-center bipolar cells synapse in the most proximal $45 \%$ of the IPL (sublamina B). Sublamina A apparently corresponds to a larger fraction of the IPL in the salamander retina than it does in the cat retina, where these sublaminas were first defined (on the basis of the stratification of OFF-center and ON-center ganglion cells) (Nelson et al., 1978). In other species the division between the two sublaminas is not so well defined. In the rat retina, for instance, bipolar cells ramifying in the very center of the IPL may receive OFF-center excitation via electrical synapses with amacrine cells, but they show little direct sensitivity to either kainate or APB (Euler et al., 1996). Also in the turtle retina, where both bipolar cells and ganglion cells are predominately multistratified, the ON-center-OFF-center border is not sharply demarcated (Ammermuller and Kolb, 1995). In the salamander retina, on the other hand, only a very small fraction of bipolar cells stratify at both distal and proximal levels of the IPL, and the division between sublaminas A and B is very clear. It is interesting that those multistratified cells that do ramify in both sublaminas appear to possess both ON-center and OFF-center synaptic conductance mechanisms. This suggests a strong developmental link between the level(s) at which bipolar cell axon terminals stratify in the IPL and the type(s) of glutamate receptors they express at photoreceptor synapses.

Although sEPSCs are clearly associated with photoreceptor inputs to HBCs, analogous (but sign-inverted) spontaneous synaptic currents are generally not apparent in DBCs [see $\mathrm{Wu}$ and Maple (1998), however]. This probably reflects a difference in the kinetics of the glutamate receptors on these two types of cells. Photoreceptor synapses on DBCs use L-AP-4 metabotropic glutamate receptors, which generate relatively slow conductance changes via a second messenger system (Slaughter and Miller, 1981; Nawy and Jahr, 1990). Therefore, the postsynaptic response to transmitter release from a single vesicle, or cluster of vesicles, at a photoreceptor synapse is likely to be heavily filtered in DBCs. HBCs, on the other hand, use rapidly activating ionotropic AMPA receptors (Slaughter and Miller, 1983; Hughes et al., 1992), which are capable of generating sEPSCs with a rise time of $\sim 1$ msec. The difference in the kinetics of these two types of receptors may be functionally relevant to the processing of visual information in the IPL. Because HBCs are inherently noisier than DBCs (Ashmore and Copenhagen, 1980), excitatory input to the IPL is noisier, overall, in the dark than in bright light (Donner et al., 1990). This trend is reinforced by a difference in the size of sEPSCs in rod- and cone-dominated HBCs. The sEPSCs appear to be smaller, on average, in cone-dominated HBCs, and this also has the effect of making excitatory inputs to the IPL less noisy under scotopic conditions than under photopic conditions. Perhaps it is advantageous for the retina to operate in a more stochastic mode when analyzing dim signals and a less stochastic mode when analyzing bright signals (Ashmore and Falk, 1981). Large voltage fluctuations in rod-dominated HBCs probably play a significant role in generating the high frequency of spontaneous action potentials observed in dark-adapted ganglion cells.

\section{Rod and cone channels}

Using spectral difference measurements, we found that the most rod-dominated DBCs (type 10) ramify very near the proximal margin of the IPL. A similar stratification has been described for rod bipolar cells of many other species (Kolb and Famiglietti, 1974; Ammermuller and Kolb, 1995; Euler et al., 1996). Salamander retinas differ from mammalian retinas, however, in that they possess rod-dominated HBCs (Hensley et al., 1993). We have observed that the most rod-dominated salamander HBCs ramify very near the distal margin of the IPL. Moreover, for both 
HBCs and DBCs, the relative strength of rod inputs tends to decrease as the level of ramification becomes more central in the IPL. It should be noted that the balance of rod and cone inputs to bipolar cells may be affected by various experimental conditions, including the state of light adaptation and the composition of the Ringer's solution. Under the somewhat light-adapted conditions described here, the difference between the sensitivities of the most rod-dominated and most cone-dominated cells is smaller than observed under strongly dark-adapted conditions (Yang and $\mathrm{Wu}$, 1997). Also, the absence of bicarbonate in our Ringer's solution may have shifted the rod and cone balance in favor of the cones (Hare and Owen, 1998), although this is not clear (Yang and $\mathrm{Wu}, 1999)$. Regardless of how such factors may modulate the rod and cone balance, our data suggest that cone signals are transmitted predominantly to the central IPL and rod signals are sent predominantly to the margins of the IPL.

Accompanying these gradients of rod and cone dominance in the IPL are differences in the kinetics of bipolar cell OFF responses; i.e., the cone input to bipolar cells moves rapidly toward (and overshoots) its steady-state dark level, whereas the rod input relaxes more slowly toward its dark level. Although cones probably contribute to the OFF overshoots observed in conedominated HBCs, the overshoots may also be mediated by a class of $\operatorname{rod}\left(\operatorname{Rod}_{C}\right)$ that is strongly electrically coupled to cones and exhibits very large transient depolarizing overshoots at light OFF (Wu, 1988; Wu and Yang, 1988). This might explain why sizable OFF tails were observed in the type $5 \mathrm{HBCs}$. For these cells the OFF overshoots are so much larger than $I_{C} \mathrm{ON}$ that the tail phase of the OFF response might be dominated by the dynamics of $\operatorname{Rod}_{\mathrm{C}}$ photoreceptors.

Although the OFF responses of cone-dominated DBCs are partially transient, they never exhibit the large overshoots present in the responses of cone-dominated HBCs. Again, this probably reflects a difference between the glutamate receptors of DBCs and HBCs; rapid transients are heavily filtered by the L-AP-4 receptor mechanism of $\mathrm{DBCs}$, but not by the AMPA receptor mechanism of HBCs. The OFF transients of HBCs may be important for motion detection (Miller, 1979), so it is perhaps worth emphasizing that these signals are most strongly expressed in the proximal portion of sublamina A.

\section{Inhibitory interactions in the IPL}

The pharmacology of the inhibitory inputs discussed in this paper has not been well described, but this inhibition is probably generated primarily by GABAergic amacrine cell synapses in the IPL (Maple and Wu, 1996, 1998). Most bipolar cells receive chloride-mediated inhibition at both light onset and offset, and much of this inhibition is probably generated by $\mathrm{ON}-\mathrm{OFF}$ amacrine cells, which ramify in both sublamina A and sublamina B and are excited both at light onset and light offset (Vallerga, 1981). The size and kinetics of these chloride currents vary greatly among different bipolar cell types, and numerous circuits are probably involved in the generation of this inhibition. One possible circuit is suggested by the fact that a particularly strong and transient $\Delta I_{\mathrm{Cl}} \mathrm{OFF}$ was observed for bipolar cells with ramifications near the very center of the IPL. Because the cells with the largest excitatory overshoots (the most cone-dominated HBCs) also ramify near the very center of the IPL, it seems likely that they provide strong excitatory OFF input to the amacrine cells that generate this strong, transient $\Delta I_{\mathrm{Cl}} \mathrm{OFF}$.

The center/surround nature of these inhibitory inputs has not yet been investigated, but a few points should be noted concern- ing receptive field organization. First, this inhibition cannot mediate surround antagonism of $\mathrm{HBC}$ responses to light onset, because it is synergistic with the photoreceptor inputs. $\left[E_{\mathrm{C} 1}\right.$ is probably near $-60 \mathrm{mV}$ in bipolar cells (Maple and $\mathrm{Wu}, 1998$ ). This is negative to the resting potential of bipolar cells in darkness and to potentials at which bipolar cell synaptic calcium conductances are measurably activated (Heidelberger and Matthews, 1992).] On the other hand, OFF inhibition can antagonize the excitatory OFF overshoots observed in HBCs. In other words, inhibitory inputs from amacrine cells do not contribute to a static inhibitory surround in $\mathrm{HBCs}$, but they might be important in regulating sensitivity to transient light stimuli. In contrast, inhibitory inputs from amacrine cells could contribute to an inhibitory surround in DBCs. This is especially a possibility for the type 10, rod-dominated DBCs, which exhibit relatively sustained ON inhibition. Bipolar cell inhibitory surrounds are thought to be primarily generated via presynaptic inhibition of cones by horizontal cells (Werblin, 1977), but in the ON pathway, amacrine cells could conceivably generate an inhibitory surround for rod signals.

In summary, we have shown an orderly segregation of light response characteristics (receptive field polarity, balance of rod and cone inputs, size of EPSCs, and other kinetic parameters) by 12 types of bipolar cells with axon terminals stratifying at different levels of the IPL. This segregation simplifies the integration of visual information in the retina, and it initiates a chain of parallel processing that is elaborated in higher visual areas of the brain.

\section{REFERENCES}

Ammermuller J, Kolb H (1995) The organization of the turtle inner retina. I. ON- and OFF-center pathways. J Comp Neurol 358:1-34.

Ashmore JF, Copenhagen DR (1980) Different postsynaptic events in two types of retinal bipolar cell. Nature 288:84-86.

Ashmore JF, Falk G (1981) Photon-like signals following weak rhodopsin bleaches. Nature 289:489-491.

Boycott BB, Dowling JE (1969) Organization of the primate retina: light microscopy. Philos Trans R Soc Lond B Biol Sci 255:109-194.

Boycott BB, Wassle H (1991) Morphological classification of bipolar cells in the macaque monkey retina. Eur J Neurosci 361:1069-1088.

Donner K, Copenhagen DR, Reuter T (1990) Weber and noise adaptation in the retina of the toad Bufo marinus. J Gen Physiol 95:733-753.

Enroth-Cugell C, Robson JG (1966) The contrast sensitivity of retinal ganglion cells of the cat. J Physiol (Lond) 187:517-552.

Euler T, Wassle H (1995) Immunocytochemical identification of cone bipolar cells in the rat retina. J Comp Neurol 361:461-478.

Euler T, Schneider H, Wassle H (1996) Glutamate responses of bipolar cells in a slice preparation of the rat retina. J Neurosci 16:2934-2944.

Famiglietti Jr EV, Kolb H (1976) Structural basis for ON- and OFFcenter responses in retinal ganglion cells. Science 194:193-195.

Hare WA, Owen WG (1998) Effects of bicarbonate versus HEPES buffering on measured properties of neurons in salamander retina. Vis Neurosci 15:263-271.

Heidelberger R, Matthews G (1992) Calcium influx and calcium current in single synaptic terminals of goldfish retinal bipolar neurons. J Physiol (Lond) 447:235-256.

Hensley SH, Yang XL, Wu SM (1993) Relative contribution of rod and cone inputs to bipolar cells and ganglion cells in the tiger salamander retina. J Neurophysiol 69:2086-2098.

Hubel DH, Livingstone MS (1987) Segregation of form, color, and stereopsis in primate area 18 . J Neurosci 7:3378-3415.

Hubel DH, Wiesel TN (1977) Ferrier lecture. Functional architecture of macaque monkey visual cortex. Proc R Soc Lond B Biol Sci 198:1-59.

Hughes TE, Hermans-Borgmeyer I, Heinemann S (1992) Differential expression of glutamate receptor genes (GluR1-5) in the rat retina. Vis Neurosci 8:49-55.

Kolb H (1982) The morphology of the bipolar cells, amacrine cells and ganglion cells in the retina of the turtle Pseudemys scripta elegans. Philos Trans R Soc Lond B Biol Sci 298:355-393. 
Kolb H, Famiglietti EV (1974) Rod and cone pathways in the inner plexiform layer of cat retina. Science 186:47-49.

Maple BR, Werblin FS, Wu SM (1994) Miniature excitatory postsynaptic currents in bipolar cells of the tiger salamander retina. Vision Res 34:2357-2362.

Maple BR, Wu SM (1996) Synaptic inputs mediating bipolar cell responses in the tiger salamander retina. Vision Res 36:4015-4023.

Maple BR, Wu SM (1998) Glycinergic synaptic inputs to bipolar cells in the salamander retina. J Physiol (Lond) 506:731-744.

Miller RF (1979) The neuronal basis of ganglion cell receptive field organization and the physiology of amacrine cells. In: The neuroscience fourth study program (Schmidt FO, Worden FG, eds), pp 227-245. Cambridge, MA: MIT.

Nawy S, Jahr CE (1990) Suppression by glutamate of cGMP-activated conductance in retinal bipolar cells. Nature 346:269-271.

Nelson R, Famiglietti Jr EV, Kolb H (1978) Intracellular staining reveals different levels of stratification for on- and off-center ganglion cells in cat retina. J Neurophysiol 41:472-483.

Ramon y Cajal S (1893) La retine des vertebres. La Cellule 9:119-257. Slaughter MM, Miller RF (1981) 2-Amino-4-phosphonobutyric acid: a new pharmacological tool for retina research. Science 211:182-185.

Slaughter MM, Miller RF (1983) An excitatory amino acid antagonist blocks cone input to sign-conserving second-order retinal neurons. Science 219:1230-1232.

Vallerga S (1981) Physiological and morphological identification of amacrine cells in the retina of the larval tiger salamander. Vision Res 21:1307-1317.
Werblin FS (1977) Synaptic interactions mediating bipolar response in the retina of the tiger salamander. In: Vertebrate photoreception (Barlow HFP, ed), pp 205-230. New York: Academic.

Werblin FS (1978) Transmission along and between rods in the tiger salamander retina. J Physiol (Lond) 280:449-470.

Wu SM (1987) Synaptic connections between neurons in living slices of the larval tiger salamander retina. J Neurosci Methods 20:139-149.

Wu SM (1988) The off-overshoot responses of photoreceptors and horizontal cells in the light-adapted retinas of the tiger salamander. Exp Eye Res 47:261-268.

Wu SM, Maple BR (1998) Amino acid neurotransmitters in the retina: a functional overview. Vision Res 38:1371-1384.

Wu SM, Yang XL (1988) Electrical coupling between rods and cones in the tiger salamander retina. Proc Natl Acad Sci USA 85:275-278.

Yang XL, Wu SM (1989) Modulation of rod-cone coupling by light. Science 244:352-354.

Yang XL, Wu SM (1990) Synaptic inputs from rods and cones to horizontal cells in the tiger salamander retina. Sci China B 33:946-954.

Yang XL, Wu SM (1996) Response sensitivity and voltage gain of the rod- and cone-horizontal cell synapses in dark- and light-adapted tiger salamander retina. J Neurophysiol 76:3863-3874.

Yang XL, Wu SM (1997) Response sensitivity and voltage gain of rodand cone-bipolar cell synapses in dark-adapted tiger salamander retina. J Neurophysiol 78:2662-2673.

Yang XL, Wu SM (1999) Modulation of horizontal cell function by $\mathrm{GABA}_{\mathrm{A}}$ and $\mathrm{GABA}_{\mathrm{C}}$ receptors in dark- and light-adapted tiger salamander retina. Vis Neurosci 16:967-979. 